\title{
Segmentation of compacted and non compacted left ventricular mass with a semi-automatic method
}

Stéphanie Bricq ${ }^{1 *}$, Julien Frandon ${ }^{3}$, Daniel Fagret ${ }^{5}$, Alexandre Cochet ${ }^{1,2}$, Alexis Jacquier ${ }^{4}$, Alain Lalande ${ }^{1,2}$

From 18th Annual SCMR Scientific Sessions

Nice, France. 4-7 February 2015

\section{Background}

The diagnostic of left ventricular (LV) non compaction is still a challenge in clinical practice. There is a lack of reference method able to automatically quantify the total amount of LV trabeculations. Many algorithms have been proposed to determine endocardium and epicardium borders ranging from semi-automated to fully automated methods. However most of the methods were not designed to take into account papillary muscles and trabeculae. Here we propose a global framework to detect non-compacted, endocardium and epicardium contours with minimal user interaction, taking into

account papillary muscles and trabeculae. Preliminary results on the normal non-compacted mass obtained from 20 healthy volunteers are presented.

\section{Methods}

Proposed method is a semi-automatic one. The user has to click in the LV cavity on one slice. Using this seed, the non-compacted contour which is a homogeneous area in term of intensity, is obtained using a region growing algorithm. This non-compacted contour is then used for the initialization of a variational B-spline level-set to determine the endocardium border. This border is used

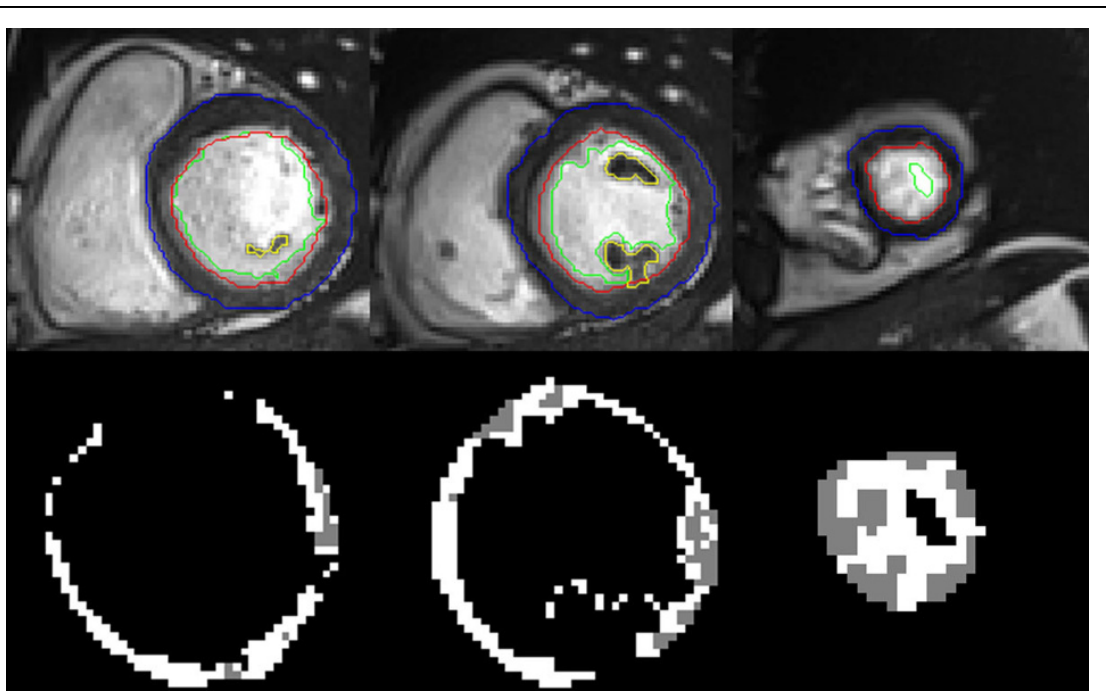

Figure 1 Example of the left ventricular segmentation from base to apex (top): epicardial border in blue, endocardial border in red, trabeculae border in green. Papillary muscles were segmented and included into the compacted mass (yellow line). For the calculation of the non compacted mass (bottom), trabeculae (grey) were segmented using a semi-automatic threshold tool to suppress blood (white).

'Le2i UMR CNRS 6306, Dijon, France

Full list of author information is available at the end of the article

(c) 2015 Bricq et al; licensee BioMed Central Ltd. This is an Open Access article distributed under the terms of the Creative Commons 
Table 1 Data as inter-observer reproducibility of measurements from 20 subjects

\begin{tabular}{cccccc}
\hline Measurement & Observer 1 Mean \pm SD & Observer 2 Mean \pm SD & $R$ & $p$ Value & Bland-Altman Mean \pm SD \\
\hline $\mathrm{NC}[\mathrm{g}]$ & $13.8 \pm 3.3$ & $11.7 \pm 3.5$ & 0.88 & $<10^{-5}$ & $-2.11 \pm 1.68$ \\
\hline $\mathrm{C}[\mathrm{g}]$ & $104.6 \pm 21$ & $103.7 \pm 21$ & 0.98 & $<10^{-5}$ & $-0.93 \pm 4.48$ \\
\hline $\mathrm{NC} / \mathrm{BSA}\left[\mathrm{g} / \mathrm{m}^{2}\right]$ & $7.8 \pm 1.7$ & $6.6 \pm 1.6$ & 0.84 & $<10^{-5}$ & $-1.23 \pm 0.95$ \\
\hline $\mathrm{C} / \mathrm{BSA}\left[\mathrm{g} / \mathrm{m}^{2}\right]$ & $58.9 \pm 8.4$ & $58.4 \pm 8.8$ & 0.96 & $<10^{-5}$ & $-0.46 \pm 2.48$ \\
\hline EDV $\left[\mathrm{mL} / \mathrm{m}^{2}\right]$ & $73 \pm 15$ & $72 \pm 15$ & 0.99 & $<10^{-5}$ & $-0.65 \pm 1.12$ \\
\hline Ratio NC/C $[\%]$ & $13 \pm 3$ & $11 \pm 3$ & 0.81 & $<10^{-4}$ & $2.02 \pm 1.7$ \\
\hline
\end{tabular}

as initialization for a region growing algorithm to obtain the epicardial border. Papillary muscles and trabeculations are then segmented using a semi-automatic threshold tool. Finally, compacted (C) mass, non-compacted (NC) mass, end-diastolic volume (EDV) and $\mathrm{NC} / \mathrm{C}$ ratio are computed.

Analysis was performed on MR examinations obtained from twenty healthy subjects (mean age $46 \pm 17$ years, 8 men). All subjects were completely asymptomatic with no known risk factors or history of cardiac disease. Segmentation was performed by two independent observers on the diastolic frame from contiguous short axis cine-MR images covering the LV. Inter-observer measurement reproducibility was assessed thanks to Bland-Altman analysis and to the correlation coefficient calculation between the different volumes obtained by the two observers.

\section{Results}

Total processing time is less than 20 min for each patient. Figure 1 shows an example of the segmentation. Absolute values of all the parameters for normal subjects are presented in Table 1, as the inter-observer evaluation. The compacted mass is around $58 \mathrm{~g} / \mathrm{m} 2$ and the non-compacted around $7 \mathrm{~g} / \mathrm{m} 2$. Correlation coefficient between the 2 observers is high, from 0.81 to $0.99\left(\mathrm{p}<10^{-4}\right)$.

\section{Conclusions}

This semi-automatic method is highly reproducible and can be used to help diagnosis in LVNC patient and probably in first degree relative of patient with hypertrophic cardiomyopathy. Our first results show that the noncompacted mass in normal subjects is widely less than 10 $\mathrm{g} / \mathrm{m} 2$ and the ratio between non compacted and compacted mass is always less than $15 \%$.

\section{Funding}

N/A.

\section{Authors' details}

'Le2i UMR CNRS 6306, Dijon, France. '2Service d'IRM, CHU Dijon, Dijon, France. ${ }^{3}$ Service de radiologie, CHU Grenoble, Grenoble, France. ${ }^{4}$ Service de radiologie, CHU La Timone, Marseille, France. ${ }^{5}$ Médecine Nucléaire, CHU Grenoble, Grenoble, France.
Published: 3 February 2015

doi:10.1186/1532-429X-17-S1-P55

Cite this article as: Bricq et al:: Segmentation of compacted and non compacted left ventricular mass with a semi-automatic method. Journal of Cardiovascular Magnetic Resonance 2015 17(Suppl 1):P55.
Submit your next manuscript to BioMed Central and take full advantage of:

- Convenient online submission

- Thorough peer review

- No space constraints or color figure charges

- Immediate publication on acceptance

- Inclusion in PubMed, CAS, Scopus and Google Scholar

- Research which is freely available for redistribution

Submit your manuscript at www.biomedcentral.com/submit 